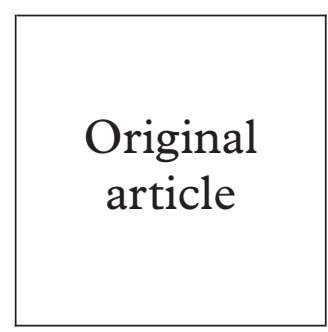

\section{When recurrent genital sores are not genital herpes}

\author{
Harisadhan Maiti, M Al-Izzi
}

Recurrent genital herpes is a common cause of soreness in the genital area in both sexes. Sometimes, even with negative viral cultures, a clinical diagnosis of genital herpes is made, especially when the patient and/or the partner suffers from genital or labial herpes. We report here a patient with recurrent vaginal soreness due to "transplantation" endometriosis.

\section{Case report}

A 32 year old married woman attended the genitourinary medicine clinic at Hertford County Hospital, requesting investigation for genital herpes. She previously had a normal delivery with an episiotomy in 1984 . She complained of soreness in the vagina lasting 4-5 days every month for 3 years, ever since she had a total hysterectomy in March 1994. The symptoms usually started about the time she was supposed to have her periods. On that day she reported that she had an attack which had started 2 days previously. There was no history of periodic anal bleeding, discomfort, or pain. Her husband suffers from "cold sores", but she has never had labial herpes and she did not admit to oral sex. She had attended a neighbouring genitourinary medicine clinic several times and was told that she was suffering from genital herpes, although herpes simplex virus was never isolated. The situation was causing a lot of strain in her marriage.

In April 1992 she had a laparoscopy because of dyspareunia and lower abdominal pain. A diagnosis of ovarian endometriosis was confirmed in laparoscopy. At that time she was also found to have cystocele, rectocele, and first degree uterine prolapse. She was treated with norethisterone for 3 months with some relief of symptoms, but she did not continue with the treatment because of headaches and she refused to take danazol. As she was still complaining of lower abdominal pain and dyspareunia she was referred to Queen Charlotte's Hospital by her general practitioner and on 4 November 1992 a Manchester repair was carried out there. Although there seemed to be initial improvement of symptoms she continued to complain of pain and a total abdominal hysterectomy was carried out on 22 March 1994. The ovaries looked normal and were conserved. The histopathology of the uterus was normal. In June 1996 division of vaginal scars was undertaken in another hospital in London, as she was complaining of vaginal soreness.

On examination bluish spots (fig 1) were visible on the scar line in the lower part of the posterior vaginal wall. A provisional diagnosis

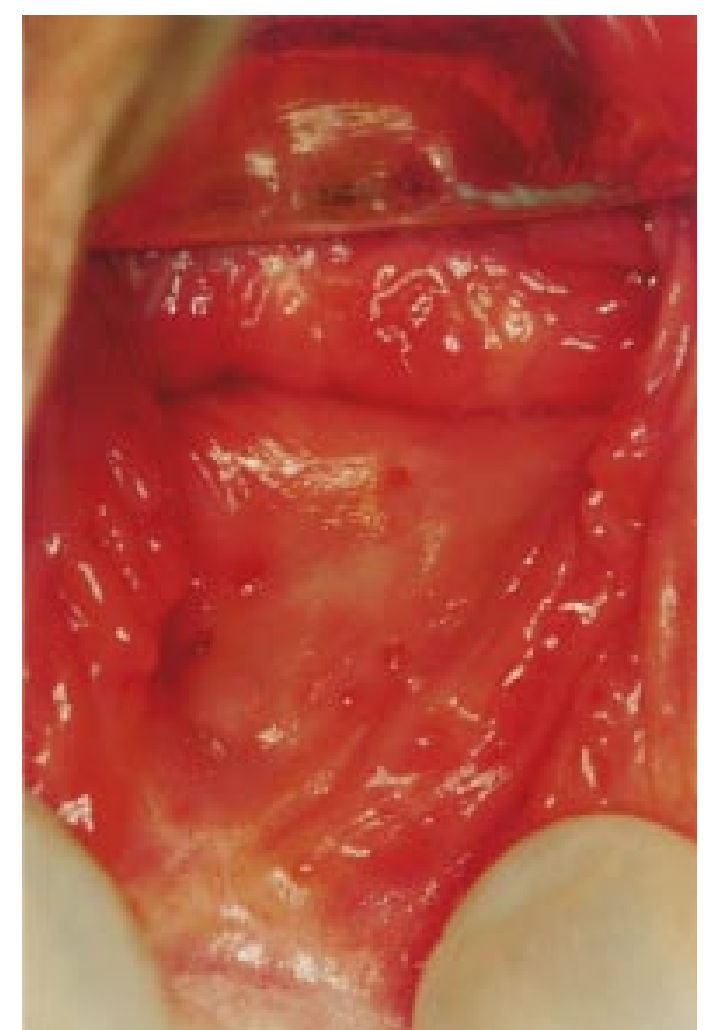

Figure 1 Bluish spots on the scar line in the lower vagina.

of endometriosis was made and a biopsy taken. The herpes virus culture taken from the lesion was negative. Histology of the specimen shows vaginal wall biopsy covered by mature squamous epithelium. There are glandular spaces in the stroma. These are lined by cuboidal and columnar cells. The cytoplasm is eosinophilic and there is no intracellular mucin (fig 2). In some areas these glands are surrounded by cellular stroma (of the endometrial type) (fig 3 ). The morphology is that of vaginal endometriosis. It was decided to cauterise the spots with a hyfrecator. On the first occasion she was not symptomatic and on examination only two endometriotic spots were visible. These were cauterised with hyfrecator under local infiltration anaesthesia with $1 \%$ lignocaine solution. She was always reluctant to come for follow up and was therefore advised to come if and when she was symptomatic.

The second time she attended 3 days after the symptoms started and on examination a few spots were visible on the posterior vaginal wall. These were cauterised as before and she was again advised to come at the onset of symptoms so that all the lesions could be dealt with. She attended 3 months later and reported that, although she was much better than 


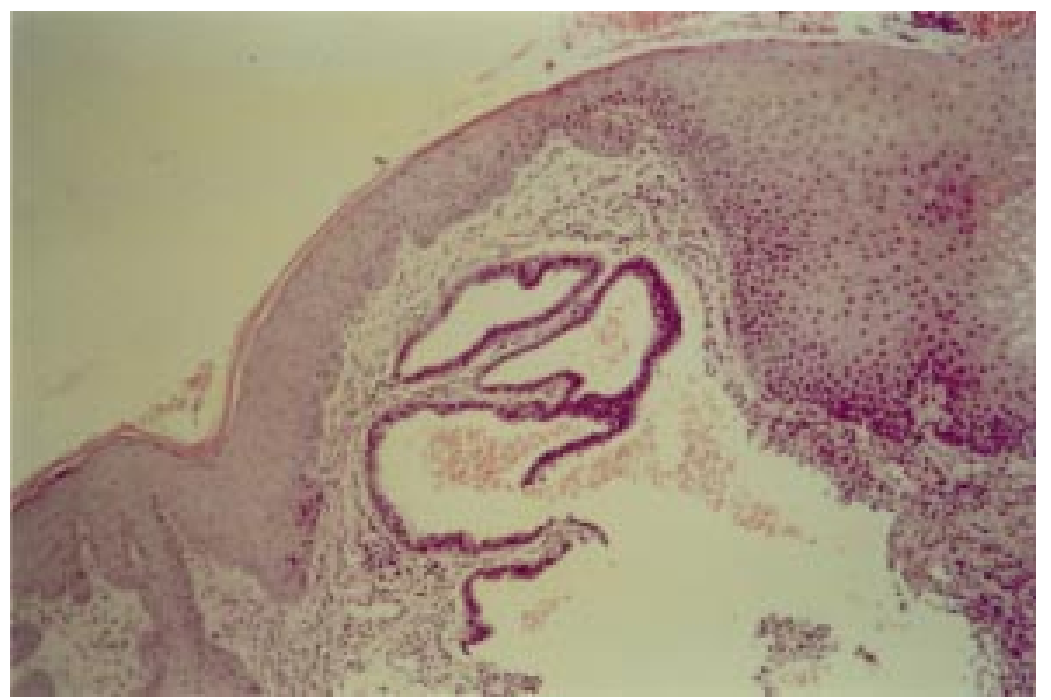

Figure 2 Mature vaginal squamous epithelium with underlying cystic glandular spaces. $\times 25$.

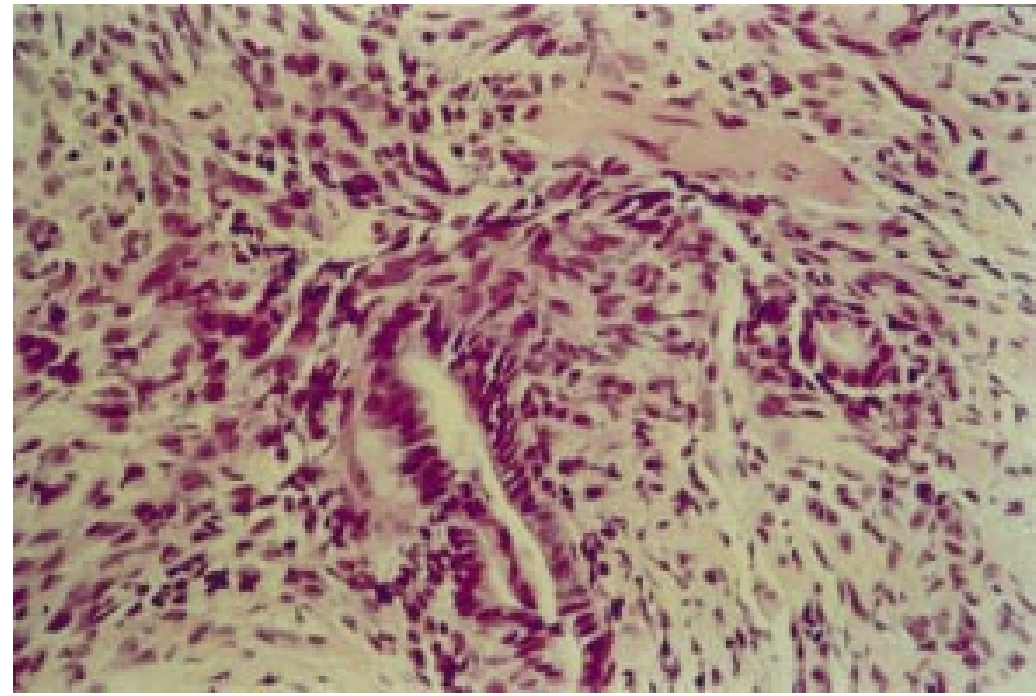

Figure 3 Glandular structures surrounded by endometrial stroma. $\times 400$.

before, there was still some problem. She was asymptomatic on that day. This time a few other spots were cauterised. Finally she did come on 13 March 1998 immediately at the onset of symptoms when all the visible endometriotic spots were cauterised with hyfrecator. She has not attended the clinic or her general practitioner so far since then.

\section{Discussion}

Endometriosis is the presence of functioning endometrial tissue outside the normal uterine lining. It is usually confined to pelvic organs like the ovaries, fallopian tubes, rectovaginal septum, uterovesical peritoneum, and pelvic peritoneum, but remote sites like the vagina, cervix, and ureters may also be affected..$^{1-6}$ In about $50 \%$ of cases there is a history of previous pelvic surgery. ${ }^{2}$ Iatrogenic transplantation endometriosis has been reported in abdominal incisions, vaginal lacerations and episiotomy scars following surgical procedures in which the uterine cavity was opened. ${ }^{278}$ Other theories of endometriosis are: (a) embryological and metaplastic; (b) haematogenous and lymphatic spread; (c) hormonal; (d) retrograde menstrual flow; and (e) genetic predisposition and immune alteration.

Endometriosis can undergo malignant change (endometrioid adenocarcinoma), the ovaries being the commonest site, ${ }^{9}$ and the rectovaginal septum is the commonest extragonadal site for malignant transformation. Malignant transformation of vaginal endometriosis is rare and only seven cases have been reported. ${ }^{10}$ Treatment of endometriosis can be classified in the following three ways:

(1) Medical management with hormones like progestogens, combined oestrogen/ progestogen preparations, danazol and gonadotrophin releasing hormone analogues. $^{211}$

(2) Surgical procedures. ${ }^{2}{ }^{412-14}$

(3) Radiotherapy-usually recommended in poor surgical risk patients with extensive lesions. ${ }^{2}$

The therapeutic choice depends on a patient's age, desire for future pregnancies, the extent of the lesions, and severity of symptoms. Carbon dioxide laser vaporisation for small vaginal lesions and endoscopic cauterisation followed by medical therapy have been recommended for isolated vesical lesions. ${ }^{12}$

\section{Conclusion}

Although endometriosis is a common gynaecological condition, ectopic vaginal endometriosis may produce similar symptoms to genital herpes and may present in genitourinary medicine departments. The case reminds us of the importance of listening to the patient, with careful examination and history taking, while keeping an open mind (back to basics) in the days of modern "high tech" medicine. Although carbon dioxide laser was recommended for isolated vaginal endometriosis ${ }^{12}$ we did not have access to laser and cauterisation with a hyfrecator seemed to be a successful method of treatment.

Azzena A, Ferrara A, Castellan L, et al. Vaginal endometriosis. Clin Exp Obstet Gynecol 1996;23:94-8.

2 Ong CL, Tung KH. Bladder endometriosis: three case reports and a review. Aust NZ F Surg 1991;61:81.

3 Kulmann M, Schindler AE. Vaginale Blutung nach Hysterektomie, Geburtshilfe- Frauenheilkd 1995;55:231-2.

4 Mazzonetto M, De Antonio M, Zennari R, et al. L'endometrosi vescicale. Osservazioni su due casi. Radiol Med 1989;77:567.

5 Shook TE, Nyberg LM. Endometriosis of the urinary tract. Urology 1988;31:1.

6 Litta P, Quinteri F, Sandei F, et al. Riflessioni su due casi di endometriosis intestinale. Atti del LXIX Congresso Nazionale della Soc It Di Ginecologia ed Ostetricia Venezia, 18-21 Ottobre 1993

7 Furbetta A, Fischeietti G, Slillitani E, et al. Endometriosi interessante l'apparato urinaro. Min Urol Nefr 1987;39:1.

8 Marquez J, Marquez JC, Arrazota JA, et al. Endometriosis extrapelviana de ubicacion perineal. Rev Chil Obstet Ginecol 1995;60:1-4

9 Brooks JJ, Wheller JE. Malignancy arising in extragonadal endometriosis. Cancer 1977;40:3065.

10 Haskel S, Chen SS, Spiegel G. Vaginal endometrioid adenocarcinoma arising in vaginal endometriosis: a case report and literture review. Gynec Oncol 1989;34:232.

11 Azzena A, Cerri G, Salmaso R. Pelvic endometriosis with histological aspects of perineural involvement. Case report 2nd Congress of Europ Soc Gyn Obst Ivestigation. Madona di Campiglio, Italy, 12-19 Feb 1995;9:(suppl 1), Parthion Publ.

12 Foster RS, Rink RC, Mulcany JJ. Vesical endometriosis: medical or surgical treatment. Urology 1987;29:64.

13 Onnis A, Marchesoni D. Endometriosi: esperienze dell scuola di Padova (terapia chirurgica). In Atti del LXV Congresso Nazionale Soc It Gin Obst, Taormina, 19 maggio-2 giugno 1988 .

14 Vernon WJ, Michael JC. Vaginal laser surgery. Obstet Gynec Clin N Am 1991;18:511. 